\title{
Os anos 1960 em revisão: um depoimento de Maurice Capovilla'
}

\author{
Entrevista e edição: Reinaldo Cardenuto²
}

I Atuando principalmente como diretor e roteirista, Maurice Capovilla iniciou a sua trajetória com os documentários políticos Meninos do Tietê (1963) e Subterrâneos do futebol (1964). Em 1967, estreou na direção de longas-metragens com o filme Bebel, garota propaganda. Desde então, realizou inúmeras obras para cinema, a exemplo de O profeta da fome (1969), O jogo da vida (1977), Harmada (2003) e Nervos de aço (201 1). Em sua passagem pela televisão, dirigiu para a rede Clobo documentários como Bahia de todos os santos (1974), O último dia de Lampião (1975) e Os homens verdes da noite (1977). Para a Bandeirantes, realizou alguns telefilmes, dentre eles A mulher diaba (1980) e O boi misterioso e o vaqueiro menino (1980).

2 Reinaldo Cardenuto é doutorando em Meios e processos audiovisuais pela ECA-USP e professor de História do cinema na FAAP. Entre 2012 e 2013, publicou os artigos "Dramaturgia de avaliação: o teatro político dos anos 1970" (revista Estudos avançados,

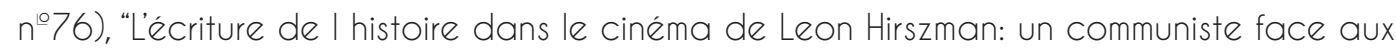
contradictions du mouvement ouvrier" (revista Cinémas d'Amérique Latine, nº21) e "A sobrevida da dramaturgia comunista na televisão dos anos de 1970: o percurso de um realismo crítico em negociação" (capítulo do livro Comunistas brasileiros: cultura política e produção cultural). E-mail: reicar@uol.com.br 


\section{Resumo}

Em 2007, como parte de minhas pesquisas para o mestrado, realizei uma entrevista com o diretor Maurice Capovilla em torno de sua atuação política e cinematográfica durante os anos 1960 e 1964. Relido e atualizado pelo cineasta em 2013, o depoimento lança um olhar crítico sobre um período histórico de intensa polarização ideológica, quando uma grande parcela dos artistas brasileiros se voltaram para um fazer poético comprometido com a intervenção social. Na entrevista a seguir, Capovilla revisita a própria trajetória intelectual, debate a sua passagem pelo Centro Popular de Cultura de São Paulo e as críticas que escreveu para a Revista brasiliense, propondo a partir desse esforço de memória uma análise de sua antiga aposta no cinema como instrumento político de ação.

\section{Palavras-Chave}

Cinema Novo, Maurice Capovilla, Partido comunista brasileiro, Centro Popular de Cultura de São Paulo, Revista brasiliense.

\section{Abstract}

In 2007, as part of my research for the master's degree, I conducted an interview with director Maurice Capovilla focusing on his political and cinematographic process from 1960 to 1964 . Revised and updated in 2013 by the filmmaker, the testimony casts a critical glance over a historical period of intense ideological polarization, when a large number of Brazilian artists turned to an artistic creation intensely committed to social intervention. In the following interview, Capovilla revisits his intellectual trajectory, debating its passage through the Centro Popular de Cultura of São Paulo and the critiques he wrote for the Revista Brasiliense, proposing an analysis of his old beliefs on filmmaking as a political weapon.

\section{Keywords}

Cinema Novo, Maurice Capovilla, Brazilian communist party, Centro Popular de Cultura of São Paulo, Revista brasiliense. 
ano 2 número 4

1. Capovilla, você poderia relembrar o início de sua trajetória no cinema?

Eu sempre fui um freqüentador assíduo das salas de cinema em Campinas, cidade onde morei quando fiz os dois primeiros anos do curso clássico de formação educacional. Em 1959, quando me mudei para São Paulo, um ano antes de ingressar na faculdade de filosofia, descobri que a cidade possuía uma ampla programação de filmes voltada para o debate sobre a atividade cinematográfica. Foi então que comecei a participar dos cineclubes.

Primeiro conheci o Dom Vidal, espaço que era dirigido por um padre e por um grupo de jovens que militava politicamente e culturalmente no universo da igreja católica. Pouco tempo depois, me apresentaram a outro cineclube, que era localizado na Rua Sete de Abril, e que funcionava na antiga filmoteca do Museu de Arte Moderna. Nesta época, por coincidência, eu era colega do Gustavo Dahl no terceiro ano do curso clássico. Nós costumávamos acompanhar as sessões paralelas à programação cinematográfica norte-americana e, volta e meia, éramos espectadores das palestras, discussões e análises críticas promovidas por Rudá de Andrade e Paulo Emílio Salles Gomes. Minha introdução ao cinema foi como um jovem entusiasta dos cineclubes, encantado com a descoberta dos processos criativos existentes no interior de um filme.

\section{E é neste momento que você começa a escrever sobre cinema?}

Ainda não. Em 1960, quando eu já cursava a faculdade de filosofia, participei de um concurso para trabalhar como repórter no Estadão. Eu e o Vladimir Herzog, meu colega na época, conseguimos uma vaga no jornal diário. Lembro que nós dois não éramos meros espectadores de cinema. Éramos jovens analistas e acreditávamos que os filmes representavam uma forma de compreender o mundo. Mas neste período em que trabalhei no Estadão, cerca de um ano e meio, não escrevi sequer uma linha sobre cinema. Em 1961, quando o Gustavo 
Dahl ganhou uma bolsa de estudos do Itamaraty, por indicação de Paulo Emílio Salles Gomes, para cursar o Centro Experimental de Cinematografia de Roma, fui convidado pelo Rudá de Andrade para substituí-lo no setor de difusão cultural da Cinemateca Brasileira. Ou seja, eu me aproximei do cinema como freqüentador de cineclubes e, pouco tempo depois, como funcionário da Cinemateca, me tornava um divulgador e fomentador da própria atividade cineclubista.

\section{E você já militava no Partido Comunista Brasileiro?}

Eu me filiei ao Partido exatamente em 1961, mas participava de suas reuniões desde que entrei na universidade. Eu morei em uma casa na Rua Maranhão, centro da cidade, que se chamava Pensão do Cotrim. O Paulo Cotrim era um sujeito ligado ao meio cultural, amigo pessoal do Vinicius de Moraes, que certo dia resolveu transformar sua residência em uma pensão para a juventude. O clima descontraído do lugar acabou atraindo o pessoal que estudava artes, música, teatro... Mas não pense que era fácil conseguir uma vaga naquela pensão. Havia um rigoroso interrogatório e uma série de condições para integrar a família do Cotrim.

Foi ali que nasceu o Teatro Oficina, com ensaios no porão da casa; foi ali que surgiu a idéia do João Sebastião Bar, espaço que lançou a Bossa Nova em São Paulo; e foi ali que eu acompanhei muitas conversas sobre política. Meu processo de formação foi complementado pelas bebedeiras no Bar Redondo e pelas inúmeras passagens no Teatro de Arena. Havia um clima de politização na cidade. Fiquei amigo do Gianfrancesco Guarnieri, do Juca de Oliveira e da Joana Fomm, frequentei um dos seminários de dramaturgia realizado pelo Augusto Boal e lá no Arena descobri que muitos atores estavam se filiando ao Partido Comunista Brasileiro. Quando eu entrei no Centro Popular de Cultura de São Paulo, em 1962, já era membro do Partidão. 


\section{Como foi sua participação no PCB e no CPC de São Paulo?}

ano 2 número 4

Entrevista

Como eu atuava no cinema, trabalhando na Cinemateca, fui militante da área artística dentro do Partido comunista. O Partidão, no período, não chegou a formular um programa político voltado para a cultura. Para a diretoria, a cultura não era uma preocupação imediata. Antes de fazer cinema, teatro ou música, os integrantes do Partido deveriam agitar e organizar as massas para a revolução social. A diretoria tentava nos impor tarefas distantes da área cultural, mas não conseguia. Nós canalizamos as nossas tarefas políticas no Centro Popular de Cultura, setor cultural de militância que, em São Paulo, não era muito bem recebido pelo partido comunista.

Quando o Rudá de Andrade e eu nos aproximamos do Sindicato de construção civil para montar um cineclube e debater cinema com os trabalhadores, não recebi apoio do Partidão, que considerava a nossa atividade inútil para os rumos de uma revolução. O Centro Popular de Cultura em São Paulo nasceu como um dos braços do CPC da UNE, entidade carioca que surgiu em 1961 a partir de um projeto do Oduvaldo Vianna Filho, do Carlos Estevam Martins e do Leon Hirszman. Diferente do Rio, onde o CPC ficava no mesmo prédio da União Nacional dos Estudantes, nós não estabelecemos uma parceria com a insípida União Estadual dos Estudantes e nem construímos uma relação direta com a universidade. Na verdade, o CPC em São Paulo foi concebido a partir do Teatro de Arena, dos artistas plásticos e de parte dos funcionários da Cinemateca Brasileira.

\section{E como foi o funcionamento do CPC em São Paulo?}

Enquanto no Rio de Janeiro o CPC tinha sede própria, militava diariamente, conseguia arrecadar dinheiro para suas atividades e influenciar o meio artístico, em São Paulo éramos mais fracos. De forma improvisada e com o apoio do Caio Graco Prado, filho do Caio Prado Jr., nos reuníamos uma vez por semana no último andar do prédio da editora Brasiliense, que ficava na Rua Barão de Itapetininga. O Caio Graco era dono dessa editora, um jovem 
muito entusiasta, freqüentador do Teatro de Arena, mas que diferente do pai não era integrante do PCB.

Em São Paulo, o CPC não contou com uma entidade que centralizasse o seu projeto, como foi o caso da UNE no Rio de Janeiro. Fomos um grupo que procurou, mesmo com dificuldades, reunir a militância cultural paulista que naquele momento encontrava-se dispersa. A nossa atuação se concentrou em duas direções. O pessoal do Teatro de Arena foi militar no Sindicato dos metalúrgicos, encenar peças nesse que era um dos sindicatos mais fortes e organizados de São Paulo, enquanto nós do cinema fomos para o Sindicato da construção civil, uma entidade presidida por um membro do Partidão, só que muito fraca para um contingente enorme de trabalhadores. E havia mais operários da construção civil do que metalúrgicos...

Estávamos no início da década de 1960, a cidade crescia assustadoramente e, de repente, com o aumento da migração nordestina, o número de operários também aumentou consideravelmente. A Avenida Brigadeiro Luís Antônio, por exemplo, tinha mais de quarenta prédios sendo construídos ao mesmo tempo. Queríamos chegar nesse povo que era mais despreparado, mal remunerado, destruído pelo consumo violento. Quando escolhemos o Sindicato da construção civil para atuar, nossa principal tentativa era convencer um sem-número de novos trabalhadores da importância da sindicalização como forma de proteção, de luta por seus direitos trabalhistas.

6. Quais os meios que vocês utilizaram na tentativa de politizar os operários?

Acreditávamos no cinema como uma forma de conscientização e agitação política. Resolvemos criar um cineclube, mostrar filmes que tratassem de temáticas operárias, com a certeza de que os trabalhadores automaticamente se interessariam por nossas discussões. Começamos exibindo $O$ encouraçado potemkin (1925), de Serguei Eisenstein, Chuva (1929), do Joris Ivens, e percebemos que a improvisada sala de cinema ficava quase sempre vazia. Só descobrimos que os operários não se interessavam por uma produção tão cabeça 
quando exibimos Zuiderzeewerken (1930), um outro filme do Ivens. Levou uns dois ou três meses para esse cineclube começar a agregar os trabalhadores. A experiência, mesmo falha, foi a nossa primeira tentativa de politizar os operários a partir do cinema.

Algum tempo depois, percebemos que nossa militância em prol da sindicalização não poderia se restringir aos cinqüenta freqüentadores de nosso cineclube. Precisávamos encontrar uma forma mais eficaz de atingir os novos operários que surgiam do processo de migração. Foi aí que nasceu a idéia de realizar um curta-metragem sobre a sindicalização urbana como for ma de defesa dos trabalhadores. Formamos um pequeno núcleo de produção cinematográfica dentro do Sindicato da construção civil e, junto aos operários, começamos a escrever o roteiro de União.

7. E esse filme foi finalizado?

Não. Infelizmente não. Ele foi montado, mas nunca sonorizado. Nós filmamos com uma câmera 16 milímetros e não chegamos a gravar o som para a dublagem. Os negativos ficaram no Sindicato e em 1964, com o golpe, desapareceram.

8. Apesar do curta-metragem não existir, eu fico muito curioso com sua experiência no Sindicato. Quer dizer... enquanto o CPC do Rio realizou o Cinco vezes favela (1962), um filme roteirizado e dirigido por jovens de classe média com pretensões artísticas, ou seja, de cima para baixo, O CPC de São Paulo tentou produzir um audiovisual em parceria com os operários...

Pois é. A começar pelo tema do filme, sugerido não por nós, mas pela própria diretoria do Sindicato. Escolhemos o tema da sindicalização não porque precisávamos dele para validar nossa militância política, mas porque o considerávamos necessário para os operários. Era um filme "chapa branca" do Sindicato, porque a sua diretoria queria mostrar aos operários as vantagens da sindicalização. Diariamente, sabíamos de trabalhadores que eram injustamente demitidos ou que sofriam acidentes de trabalho e, como não possuíam vínculo 
empregatício, ficavam completamente desamparados, sem destino na cidade de São Paulo. A partir do filme, queríamos mostrar aos operários a vantagem de uma carteira assinada, a vantagem de pagar o Sindicato e adquirir segurança no trabalho. O objetivo era prático e simples: vender o Sindicato. Era um comercial.

Para realizar um filme sobre o operariado, um cotidiano bem distante da vida de jovens de classe média, chegamos à conclusão que deveríamos criar o roteiro junto aos trabalhadores. Após as exibições semanais do cineclube, o Rudá e eu nos reuníamos no próprio Sindicato para discutir nossas idéias. Aos poucos foi surgindo um roteiro bem primitivo e linear: o filme começava com um operário caindo de um andaime. Os colegas de trabalho se solidarizam com o acidentado e tentam convencer o mestre de obras e o gerente da empresa para que cuidem do rapaz. Há um conflito entre os grupos mas, no final, não haverá auxílio ao rapaz. O aviso: se aquele operário da construção civil fosse sindicalizado, certamente ele receberia cuidados médicos.

Foi um institucional que contou com a ajuda dos trabalhadores. Eles que traçaram as ações do filme, que definiram o acidente como elemento dramático do roteiro. Foi impressionante a preocupação deles com os detalhes: o operário do filme deveria aparecer sem luvas e capacete, já que a segurança nas construções era mínima. O objetivo era expor a precariedade, a remuneração baixíssima, a opressão... tudo um pouco exagerado, dentro daquele espírito bem eisensteiniano que contagiou a minha geração.

Para você ter uma idéia do que eu quero dizer com isso, basta lembrar do personagem do gerente da empresa. Era um alemão forte, um amigo meu chamado João Marschner, crítico de teatro do Estadão, que visualmente se opunha ao operário franzino. Eu queria estabelecer um jogo dialético: o capitalista encorpado, que vive bem e se alimenta todos os dias; e o proletário fraco, que subsiste na cidade grande. Chegamos inclusive a traçar um plano de exibição. Sairíamos à noite com um projetor para mostrar o filme dentro das construções. 


\section{E qual foi o destino do CPC em São Paulo?}

ano 2 número 4

Depois de alguns meses de trabalho, no início de 1963, nós encerramos as atividades do CPC. Desde o início, enfrentamos inúmeras resistências do Partido Comunista, que desprezava nossa proposta cultural e nos tachava de românticos. Para eles, a revolução aconteceria apenas no nível político, o que excluía qualquer possibilidade de utilizar a arte para transformar a sociedade.

Com o passar do tempo, a relação tumultuada foi se transformando em uma relação impossível. Os conflitos aumentavam diariamente e chegou um momento em que artistas de peso começaram a bater de frente com o Partido. As posições antissectárias de Gianfrancesco Guarnieri, do Caio Graco, de Juca Oliveira ou do Teatro de Arena repercutiram nacionalmente. Até o Prestes acabou envolvido na discussão.

Me recordo que dentro do CPC de São Paulo, o partido criou um núcleo de militantes com o objetivo de analisar, orientar e corrigir as nossas atividades. Então, imagina a situação... Nós renegávamos o ponto de vista do Partido sobre a cultura e éramos obrigados a servi-lo politicamente...

Para suavizar o conflito, o diretório municipal organizou uma reunião com um de seus ilustres membros, o Mário Schemberg, considerado até hoje o maior físico do país. Ele presidiu uma sessão, aparentemente sem nenhum sentido, em que nós debatemos, com o comitê central do Partido, a função da cultura e sua aplicação na realidade. Apesar dessa rápida tentativa de estabelecer um diálogo, o CPC foi dissolvido logo depois. Interrompi minhas atividades no Sindicato da Construção Civil e parti para a realização de meu primeiro curtametragem, o Meninos do Tietê (1963).

10. De 1961 a 1964, além de repórter, funcionário da Cinemateca, militante do CPC e cineasta, você publicou na Revista brasiliense críticas engajadas sobre os filmes brasileiros da época...

Sim... não me recordo bem como fui convidado para escrever na Brasiliense. Talvez o Elias Chaves Neto, que era editor da revista... A Revista, que deu apoio 
ao CPC, já que nossas reuniões aconteciam em um dos andares de sua sede, foi essencial para a expressão da intelectualidade de esquerda.

11. Eu gostaria de propor a você um exercício, um esforço de rememoração... Li suas críticas para a Revista brasiliense e separei alguns fragmentos que parecem sintetizar seu ponto de vista naquele momento. Minha proposta é que você comente esses trechos a partir de uma reflexão sobre o pensamento crítico no início da década de 1960.

\section{Vamos tentar.}

12. Na Revista brasiliense número 43, de setembro/outubro de 1962, você publicou um artigo chamado "Um cinema entre a burguesia e o proletário". Há um comentário sobre o papel da crítica e você sugere que ela deveria ter uma função normativa, que traçasse os pressupostos básicos para 0 cinema brasileiro e que fosse uma arma de conhecimento sociológico. Está escrito que

"se continuarmos a examinar o passado veremos que ele não nos ajuda a formular o conceito de uma linha útil para o cinema nacional. O clima do subdesenvolvimento gera no cinema, e na arte em geral, saídas falsas, seja a imitação pura e simples da metrópole, seja o populismo regionalista sincero, mas inócuo. Será preciso que o atual cinema brasileiro, com as experiências dos grupos da Bahia e do Rio, forneça uma tese para a crítica. Antes de tudo é preciso que a crítica deixe de representar a cômoda situação de juiz da criação e passe a reunir as condições elementares para ser uma tarefa normativa, com pressupostos básicos, que trace os fundamentos essenciais pelos quais se norteie a produção cinematográfica. A crítica, armada dos bons recursos do conhecimento sociológico da realidade brasileira, estará em condições de prescrever com objetividade as saídas lógicas para uma efetiva evolução do cinema nacional". 
Nessa época nós, os críticos, acreditávamos que seríamos os condutores do processo de criação cinematográfica. Penso que essa idéia de comandar a produção foi a forma distorcida como compreendemos, de longe, a experiência do Centro Experimental de Cinematografia de Roma em relação ao neor realismo. Nós líamos revistas italianas de cinema e concluíamos que os críticos possuíam um papel fundamental na obra de Zavattini, Vittorio De Sica, Rossellini ou Visconti. Naquela época, eu um jovem com pretensões críticas, acreditava que os italianos, no campo teórico, traçavam uma linha ideológica, uma forma de pensar, que poderia ser aplicada na prática cinematográfica.

Foi um pulo para que eu começasse a escrever textos com um espírito bem normativo, na busca de um modelo ideal de compor tamento para a cinematografia brasileira. Eu acreditava que as minhas análises poderiam ser vistas como uma espécie de ponto de partida e de inspiração para os cineastas. Essa posição, obviamente, não era apenas minha. A minha geração, a geração que viveu o Cinema Novo, defendeu uma análise bastante ideológica da realidade, da arte e da História a partir dos pressupostos erigidos pelo Partido Comunista. E eram pressupostos que exigiam a tomada de uma posição, exigiam que separássemos o mundo entre o que interessava e o que não interessava. Tanto que eu imagino que meus textos da Brasiliense vão muito na linha "isso aqui dá, isso aqui não dá" e "tira isso daqui, coloca aquilo ali". Vivíamos em um tempo muito "dois mais dois são quatro". Fui muito violento em relação a alguns filmes.

13. Outro ponto que aparece muito em seus artigos da Brasiliense é a afirmação de que o cinema deveria analisar a sociedade com precisão científica, como se os filmes fossem instrumentos sociológicos em busca da verdade dos fatos. Tanto é que você exige que o cinema mostre os problemas sociais e o homem brasileiro objetivamente, sem idealizá-los ou romantizá-los. Havia implícita a certeza de que as ciências sociais eram o reflexo da mais pura objetividade. E em certo momento você escreve que o "melhor caminho é o realismo crítico, que é diferente de psicologismos e subjetivismos". A partir dessa perspectiva, você analisou alguns filmes do período. É o 
caso de Aruanda (1959), de Linduarte Noronha. No artigo de maio/junho de 1961, "Cinema Novo", encontrei a seguinte opinião sobre o filme:

\footnotetext{
“Aruanda marcou data dentro do movimento, porque soube ser didático e simples, apesar de suas imperfeições técnicas, que não lhe prejudicam o conteúdo. Foi direto ao homem, sem idealizá-lo, e procurou marcar as relações econômicas que o envolviam com uma precisão científica. Utilizou a história para buscar a origem dos fatos, na seqüência em que se mostra a migração do negro Zé Bento e sua família em busca da água”.
}

Aruanda realmente foi um impacto. Uma das razões é que o filme apresentava uma nova análise do presente no meio cinematográfico. O Linduarte se propôs a reconstruir o drama social do sertanejo e a estabelecer um vínculo desse problema com o passado do país, explicando a relação existente entre a miséria e a nossa história. Mais do que isso, o documentário permitia a apreensão de um povo que era, até então, invisível nas telas de cinema. O flagelado tornavase presente e exigia um debate sobre como contornar a situação de miséria. Aruanda foi tão impactante que influenciou vários diretores do Cinema Novo. Influenciou Nelson Pereira dos Santos. Ruy Guerra resolveu investigar o sertão em Os fuzis (1963). Glauber Rocha, mesmo morador da Bahia, nunca havia adentrado o sertão. Foi o início da busca por esse homem perdido.

Quando escrevi o artigo, em 1961, enxerguei no documentário um enorme potencial realista em que a narrativa apresentava um quadro quase sociológico da situação. Nos atraía a arte que procurava explicar as contradições da nossa sociedade, que apresentava as razões históricas da pobreza brasileira. Esse filme não ocultava os problemas sociais, como era comum na época. Pelo contrário: o problema explodia na tela e exigia de nós uma solução. Muito diferente do documentário Arraial do cabo (1959), de Paulo Cesar Saraceni, que foi produzido na mesma época. Ao invés de aprofundar a análise sobre o universo do pescador, um miserável que perde seu trabalho para o processo de industrialização, Saraceni criou uma visão plástica daquele cotidiano. Não havia crítica, não explicitava a existência do conflito social. 
14. Sobre Arraial do cabo, no mesmo artigo, você escreveu que o filme era

ano 2 número 4

\section{Entrevista}

"difícil, pois tinha que tomar uma posição. Para os autores, seria reacionarismo defender os pescadores para condenar a fábrica e com ela a industrialização. Em muitas cenas, entretanto, o tratamento dado aos pescadores deixava transparecer um certo passadismo sentimental. Mas nada mais estranho aos autores do que o idealismo. De qualquer modo, Paulo Saraceni pelo menos não estava ao lado da fábrica, naquelas circunstâncias particulares, pois, segundo ele, a industrialização fora implantada de forma artificial e desintegrara o homem do lugar".

Quer dizer, o que parece ter te incomodado no filme é que Saraceni não assumiu uma posição e o fato de Arraial idealizar o pescador, se distanciar da proposta científica...

É... e a implantação daquela fábrica inter rompeu a pesca na região durante muitos anos.

\section{Lendo suas críticas, eu notei que na Revista brasiliense você escreveu} poucos comentários sobre a construção formal dos filmes brasileiros. Havia um interesse maior pela questão ideológica no cinema. Tanto é que você defendeu uma produção cinematográfica que, independente do valor artístico, tivesse como objetivo a atuação política imediata, que conscientizasse o espectador para a luta e para a revolução social. No mesmo artigo em pauta, há a seguinte sequência:

\footnotetext{
“os filmes baianos são feitos para atuar de imediato, predispondo tomadas de consciência pelo povo dos problemas mais agudos do momento. São filmes que, certamente, não entrarão na história do cinema pelo seu 'valor artístico', pois são obras condenadas a servir o momento histórico, são armas, utensílios, formas temporãs de difusão de uma cultura pragmática".
}

Mais para frente, você comenta o longa Cinco vezes favela, produção do CPC da UNE: 
“(o filme), independente do seu valor artístico, mas simplesmente pelo caráter de produção e pela posição ideológica assumida, evidentemente se revestirá de importância. Como produção independente, o filme rompe com os esquemas tradicionais da produção corrente, submetida aos capitais opressores, que medem o gosto público pelo critério do lucro comercial".

A minha visão, e de muitos da minha geração, era a de que o bom filme era o filme objetivo, utilitário, cuja finalidade seria a educação política do espectador. Estávamos mais inquietos com o destino da sociedade e com o comunismo. Não havia preocupação com a estética ou com a narrativa, mas sim, se um filme funcionava ou não em termos de conscientização e de impacto. Era uma posição muito rígida e bastante desinteressante. Não vejo a menor possibilidade de aplicá-la atualmente.

E o Cinco vezes favela foi realizado pelo CPC com esse espírito didático. Esse pressuposto de um cinema pragmático é tão falido que se você revir o filme nos dias de hoje vai notar que o único episódio coerente, que ainda possui um potencial crítico, é o Couro de gato, de Joaquim Pedro de Andrade. Concorda?

É um episódio que não foi realizado originalmente pelo CPC da UNE. O Joaquim dirigiu o curta anos antes e serviu de inspiração para o trabalho de Cacá Diegues, Miguel Borges, Marcos Farias e Leon Hirszman. Ou seja, sem a visão intencionalmente política que o CPC defendia. Couro de gato, feito sem diálogos, apenas com ações, é o único que se mantém atual. Os demais são datados.

16. Bom... em suas críticas você persiste na defesa desse cinema didático. E Vidas secas (1963), do Nelson Pereira dos Santos, aparece como grande exemplo de um filme voltado para a ação ideológica. No número 51 da Revista brasiliense, de janeiro/fevereiro de 1964, no artigo "Vidas secas", você escreve: 
prima da arte cinematográfica. 'Vidas secas' é, neste momento, uma obrade-arte cinematográfica e um instrumento completo de luta política". Você prossegue o texto dizendo que o filme é perfeito para atuar na revolução social, pois congrega dois valores: é um ótimo instrumento político e é também uma obra-prima.

Sua conclusão retoma a discussão sobre o cinema como uma ciência do social:

\begin{abstract}
“E para refutar as dúvidas quanto à destinação de 'Vidas secas' podese dizer que ele irá servir para todos aqueles que estão realmente interessados na libertação do país, isso porque é um filme claro, um filme que demonstra a evidência".
\end{abstract}

Pelo visto, essa minha crítica, feita para uma das últimas edições da Brasiliense, ultrapassou o mero utilitarismo. Realmente Vidas secas é uma obra-prima, um filme atemporal, que analisa o Nordeste com visão crítica e estética. Tanto que ainda possui atualidade, não morre...

Não sei se você sabe, mas nessa época sofríamos uma pressão muito forte da crítica considerada reacionária. No Estadão havia um crítico oficial, o Rubem Biáfora, que era um filho da mãe, um sujeito que ignorava a existência do Brasil e de sua cultura. Ele idolatrava a ar te europeia e cineastas como Bergman e Victor Sjöström. Na Folha acontecia uma situação muito parecida... Ou seja, os dois jornais mais importantes de São Paulo defendiam uma posição marcadamente anticinema brasileiro.

No Correio da manhã, jornal carioca, o Muniz Viana também fazia questão de defender um ponto de vista contra a cultura brasileira. Não havia, portanto, um jornal ou uma revista de grande circulação onde nós, defensores da tradição nacional, pudéssemos expressar nossas opiniões sobre a arte.

Portanto, o espírito por trás dessa série de artigos que eu escrevi é o de encontrar um espaço para desabafar, para debater propostas, já que não era 
fácil encontrar um meio para circular nossas idéias. Muitas vezes são textos exagerados, com frases de efeito e visão controversa, mas que funcionaram como resposta à violência da crítica reacionária. Estávamos em conflito contra forças muito fortes que nos segregavam culturalmente.

17. Agora eu vou ler sobre alguns filmes que não mereciam sua consideração...

Porra. Agora você me deixou envergonhado. Quero saber quais são...

\section{O pagador de promessas (1962)}

O pagador...

19. É um artigo publicado em julho/agosto de 1962, no número 42 da Revista brasiliense, com o título "O culto ao herói messiânico". Você não deixa de comentar que o filme é importante por abrir as portas do mercado internacional para o cinema brasileiro. Chega, inclusive, a pedir consideração da crítica pela repercussão de Anselmo Duarte no exterior. Entretanto, renega o filme por seu caráter ideológico. É um texto zangado contra o personagem principal de O pagador de promessas. Em sua opinião, o Zé do burro funciona apenas como estopim desorganizado da revolta popular, estopim messiânico que reafirma os valores da igreja católica sem transformar a massa em porta-voz da revolução. É o seu principal incômodo:

“، O pagador de promessas' pode ser fruto de uma visão de mundo definível como ‘culto ao herói messiânico'. Segundo essa visão do mundo, a principal forma revolucionária é o 'povo', ainda como idéia abstrata, aglutinada em torno de um herói mítico cuja ação se desenvolve por impulsos irracionais e incontroláveis. Não são as classes, nem a luta das classes que resolvem as contradições, mas unicamente o 'povo’ unificado pelo sacrifício ou exemplo de um indivíduo, o ‘herói', capaz de catalisar essa força popular. (...) Com 

unificado não pela consciência das suas necessidades, mas pela admiração e crença no poder de uma personalidade fora do comum, que se apresenta como o Messias da antiguidade, para a salvação".

O Zé do burro é um personagem fora dos parâmetros habituais. Para salvar seu burro, promete na Umbanda que pagará sua dívida na Igreja Católica. Ou seja, ele coloca em conflito duas visões espirituais do mundo. E é messiânico porque faz o povo se revoltar a partir da fé religiosa e não da luta política.

Quando vimos a peça do Pagador no Teatro Brasileiro da Comédia, tempos antes do Anselmo dirigir o filme, acreditamos na premissa dramática, do sujeito que deseja entrar na igreja com seu burro. Teatro é encenação. Mas quando assistimos ao filme, não sentimentos a mesma credibilidade da peça: ficava muito estranho, porque a Bahia é aquela realidade ostensiva, com aquela igreja com colunas e escadaria... Quando o cinema materializou em realidade o texto de Dias Gomes, sentimos a falsidade da narrativa, sentimos que aquele personagem nunca poderia existir em um cenário tão realista, construído em uma igreja verdadeira de uma cidade também verdadeira. Criticamos negativamente a adaptação de Anselmo.

Fora que o Zé do burro nos passava esse incômodo ideológico. Diferente do Anselmo, não víamos o messianismo com empolgação, mas como uma superstição que paralisava o povo. Quando eu dirigi O profeta da fome (1969), analisei esse fenômeno como forma de alienação. Minha crítica fica evidente na cena em que o Mojica está pregado em um cruzeiro e um grupo de romeiros se entrega fervorosamente ao culto de um suposto ser superior. Eles acreditam em um conflito que não existe...

20. Um outro filme que você descarta é Os cafajestes (1962), de Ruy Guerra. $O$ artigo, também publicado no número 42 da Brasiliense, se chama "Testemunho não é acusação". O que te incomoda ideologicamente no filme é que o Ruy filma o cotidiano e os costumes do playboy sem adotar uma posição crítica. Você sentencia que o cineasta, ao registrar a classe média sem emitir opinião, acabou por realizar um filme passivo e vazio. 
"Para Ruy Guerra, o fenômeno se apresentou como um fato despido de causas ou conseqüências. Para ele, o 'playboísmo' foi apenas matéria de registro. Seu ângulo de visão constitui na descrição do fenômeno. Daí o seu erro (...) Sempre há um compromisso do artista e de sua obra; há um compromisso até na alienação. Portanto a isenção, o abstencionismo, a imparcialidade criadora são formas negativas de tomar partido, e o pior partido por sinal".

Os cafajestes é um filme complacente, que procura chocar com a nudez da Norma Bengell. Aquela curra automobilística é totalmente exacerbada... $\mathrm{Na}$ época, não queríamos um cinema vazio, com polêmicas vazias. Eu estava aprendendo sociologia com o professor Florestan Fernandes e procurava uma arte com visão crítica sobre a sociedade. Não dava para ser diferente...

21. Para terminar, eu gostaria que você comentasse mais dois trechos da Brasiliense. Em seus artigos, você defende a idéia de que a cultura brasileira autêntica é aquela que propõe a transformação da sociedade. Na Revista brasiliense número 43, naquele artigo "Um cinema entre a burguesia e o proletariado", de setembro/outubro de 1962, você escreveu que

\footnotetext{
"não pode haver cultura autêntica se não há condicionamento ao momento histórico e nesse sentido à situação econômica, social e política do país. Na situação atual o Brasil vive em regime de urgente transformação. Uma luta se trava entre as forças renovadoras e progressistas da nação".
}

Naquele momento, nós éramos obrigados a assumir uma posição política. Não havia meio-termo, não se podia ficar em cima do muro. A nação estava bastante dividida entre os setores da esquerda e os da direita. Por isso, a cultura que defendíamos era uma cultura que respondia ao excesso de conservadorismo da arte realizada pelos reacionários. Buscávamos a renovação.

São Paulo era um centro fantástico de conservadorismo. A cultura paulista era um tripé formado pelo TBC, pela Vera Cruz e pelo Museu de Arte Moderna e montado por um único sujeito, o Ciccillo Matarazzo. Foi ele que 
moldou os pilares das artes plásticas, do cinema, do teatro, do diabo! Não que devêssemos renegar completamente a experiência da elite econômica, mas não nos sentíamos retratados ali.

Por isso críamos o Teatro de Arena, que era o subúrbio, o offside, o offbroadway... O Arena era um pouco maior que a sala da minha casa, com lugar para 100 espectadores no máximo. No cinema a mesma coisa. Assumimos uma ação e um pensamento bastante radicais.

E nesses artigos, o radicalismo está expresso. Eu defendi um cinema ligado ao presente, que refletisse, debatesse e explicasse a História que estávamos vivendo. Queria uma arte capaz de transformar o mundo.

22. No mesmo artigo do número 43 há um último assunto que eu gostaria de levantar, em relação ao público que o cinema brasileiro buscava na época. Há um conflito, que marca o Cinema Novo do começo ao fim, sobre qual seria o espectador ideal para seus filmes: proletários, burgueses... Você escreveu:

\footnotetext{
“As dubiedades ideológicas, não só do filme baiano, mas do cinema brasileiro realizado por cineastas interessados no processo social, são resultados da posição ingênua de uma classe naturalmente instável, sempre no meio do caminho da participação, indecisa quanto à finalidade da sua arte. Sem saber se devem ou não servir ao proletariado, estão na verdade preparando um novo público dentro da burguesia mais avançada. É evidente que por ora os novos cineastas brasileiros não têm condições, inclusive psicológicas, para colocar suas obras a serviço da classe que ascende, mas acontece que, mesmo para servir à burguesia progressista nacional, os cineastas precisam evoluir".
}

Aí eu virei sectário total. O cinema brasileiro que estava nascendo foi moldado pela burguesia. Os cineastas, incluindo eu mesmo, eram todos burgueses. A visão de que os filmes deveriam ser feitos obrigatoriamente para a classe operária e para o povo soa como uma frase de efeito. 
Neste trecho da minha crítica, eu tomo uma posição tão radical que chego a negar minha própria existência. É evidente que, como crítico e realizador, estou ligado ao Cinema Novo desde sua origem e me sinto muito atraído pelos filmes que meus colegas estão realizando. Então, quando disse, de modo gratuito, que os cineastas não têm condições psicológicas ou que precisam evoluir, assumi um ponto de vista distante de minhas próprias opiniões. Parece-me uma negação típica do Partidão comunista.

E não é que os autores estivessem despreparados para atingir um grande público. É que a realidade não estava pronta para receber, por exemplo, um filme como Vidas secas, que propunha uma renovação na linguagem cinematográfica... 